\title{
PYROCARBON VERSUS COBALT-CHROMIUM IN THE CONTEXT OF SPHERICAL INTERPOSITION IMPLANTS: AN IN VITRO STUDY ON CULTURED CHONDROCYTES
}

\author{
A. Hannoun ${ }^{1, *}$, G. Ouenzerfi ${ }^{1,3}$, L. Brizuela², S. Mebarek², C. Bougault², M. Hassler ${ }^{3}$, Y. Berthier ${ }^{1}$ \\ and A-M. Trunfio-Sfarghiu ${ }^{1}$ \\ ${ }^{1}$ LaMCoS CNRS UMR5259, INSA Lyon, Lyon, France \\ ${ }^{2}$ ICBMS CNRS UMR5246, University Lyon 1, Lyon, France \\ ${ }^{3}$ Wright Medical/Tornier, Grenoble, France
}

\begin{abstract}
In the context of shoulder surgical replacement, a new generation of spherical interposition implants has been developed, with the implant being a mobile spacer rubbing against the glenoid cartilage and humeral bone cavity. The aim of the present study was to compare pyrocarbon (PyC) versus cobalt-chromium (CoCr) implants, regarding preservation and regeneration of the surrounding tissues. The effect of the biomaterials on chondrocytes was analysed in vitro. Murine primary chondrocytes were grown on discs made of $\mathrm{PyC}$ or $\mathrm{CoCr}$ using two culture media to mimic either cartilage-like or bone-like conditions (CLC or BLC). Chondrocytes did grow on $\mathrm{PyC}$ and $\mathrm{CoCr}$ without alteration in cell viability or manifestation of cytotoxicity. The tissue-like cell membranes grown under BLC were examined for the chondrocyte's ability to mineralise (by alizarin red matrix staining, calcium deposit and alkaline phosphatase activity) and for their mechanical properties (by rheological tests). For the chondrocytes grown under CLC and BLC, extracellular matrix components were analysed by histological staining and immunolabelling. Under CLC, PyC promoted type II collagen expression in chondrocytes, suggesting that they may generate a more cartilage-like matrix than samples grown on both $\mathrm{CoCr}$ and plastic control. In BLC, the tissue-like cell membranes grown on PyC were more mineralised and homogenous. The mechanical results corroborated the biological data, since the elastic modulus of the tissue-like cell membranes developed on the PyC surface was higher, indicating more stiffness. Overall, the results suggested that $\mathrm{PyC}$ might be a suitable biomaterial for spherical interposition implants.
\end{abstract}

Keywords: Implant, cartilage, bone, pyrocarbon, cobalt-chromium, cultured chondrocytes, rheology.

*Address for correspondence: Amira Hannoun, Laboratory of mechanics and solid structures, INSA of Lyon, Bâtiment Sophie Germain 27bis, Avenue Jean Capelle, F69621, Villeurbanne, France.

Telephone number: +33 758375661 Email: amira.hannoun@insa-lyon.fr

Copyright policy: This article is distributed in accordance with Creative Commons Attribution Licence (http://creativecommons.org/licenses/by-sa/4.0/).

\section{Introduction}

Indications for shoulder arthroplasty include a large variety of disorders covering severe proximal humerus fractures, osteoarthritis (post-traumatic or inflammatory) and rotator cuff deficiency. Many surgical procedures are currently available, which can be divided into three main types: hemiarthroplasty (HAS), total shoulder arthroplasty (TSA) and reverse total shoulder arthroplasty (RSA) (Lévigne et al., 2010; Wiater and Fabing, 2009). Several factors must be considered when choosing a prosthesis, such as age and activity level of the patient, bone stock and rotator cuff status. HAS is primarily used in patients with healthy glenoid cartilage. However, a recent study demonstrates that TSA offers better clinical outcomes than HAS (Jacobson et al., 2014). TSA is widely used for centred glenohumeral arthritis and RSA is used for pathologies involving the rotator cuff or tuberosities (Ozturk et al., 2014). Both techniques consist in replacing the humeral section by an implant, generally made of metal (cobalt-chromium alloy, CoCr) (Levy and Copeland, 2001). Despite the overall successful results of these treatments, complications are not negligible. Complaints of a failed shoulder arthroplasty include constant or 
activity-related pain, poor range of motion and instability (Chin et al., 2006; Wiater et al., 2014). Causes of pain include problems related to surgical technique, periprosthetic infection, component wear and loosening, rotator cuff degeneration and glenoid erosion. A study by Gonzalez et al. (2011) calculates the complication rate following a TSA at $22 \%$.

Because of these inconveniences, a new generation of shoulder implants exists for the primary glenohumeral arthritis: interposition arthroplasty based on a free spherical implant (Garret et al., 2017). The implant is designed to be inserted, without fixation, between the glenoid cartilage and the surgically created humeral metaphyseal cavity. Hence, the spherical implant replaces the anatomical humeral head (Allieu, 2012). Contrarily to the TSA and RSA procedures, the design of this spherical implant is based on: (1) the absence of skeletal embedding, (2) implant mobility and (3) integrity of the tendons ensuring stabilisation.

Whereas CoCr is the most used biomaterial in shoulder arthroplasty, pyrocarbon (or pyrolytic carbon, PyC) is selected as the material for the interposition implants by Garret et al. (2017). This biomaterial has an excellent tissue biocompatibility and good wear properties (Cook et al., 1989; Gauci et al., 2016; Garret et al., 2017). Furthermore, PyC tribological properties are different from metals as it can slide against bone and cartilage without causing pain or damage (Cook et al., 1989; Cook et al., 1999). Also, it has an elastic modulus similar to that of bones (Cook et al., 1999; Kawalec et al., 1998). Of note, this type of non-fixed PyC implants have been successfully used as spacers in small joints for more than 20 years, in particular to fix fractures of the proximal pole of the scaphoid (Gras et al., 2012).

Clinical evaluations, radiographic outcomes and implant survival of PyC interposition shoulder arthroplasty are assessed at the 2-year follow-up by Garret et al. (2017) and Hudek et al. (2017). Both studies reveal satisfactory clinical results comparable to those of HAS but still inferior to those of TSA. Radiographic outcomes suggest that PyC induce minimal bone and cartilage wear. PyC spherical implants can be used for shoulder arthroplasty either in patients with a variety of osteoarthritic morphologies, where the glenoid cartilage surface is already damaged, or in patients with a healthy glenoid. In both cases, glenoid wear is of importance because it may result in pain and functional loss leading to deterioration over time. Thus, the capacity of the implant to preserve cartilage integrity or, at least, to prevent more cartilage degeneration is a source of concern. For this reason, the present study focused on the interaction between PyC and chondrocytes in a cartilage-like environment.

A PyC spherical implant also faces the humerus. In fact, to insert the shoulder interposition implant the surgeon creates a cavity in the humeral bone that reaches the metaphyseal zone. This zone contains the mesenchymal stem cells, which promote healing and regeneration, and the growth plate cartilage cells (in young patients). In a study on human explants, a neosynthesised tissue at the extremity of the humeral metaphyseal cavity in contact with PyC implant is observed. Histological analysis suggests that this new tissue has cartilage-like characteristics (unpublished data). Similarly, Kawalec et al. (1998) show in an adult beagle model that the contact between PyC and full-thickness cartilage defects, which continue to the level of the metaphysis, promotes the neosynthesis of a cartilage-like tissue. In addition, there is more tissue regeneration when using PyC implants than $\mathrm{CoCr}$ ones. In the case of spherical implants for shoulder arthroplasty, self-regeneration of the tissue at the site where the humeral bone is machined may be the determinant for clinical outcomes, if only to avoid bone wear. Because preliminary studies show a tendency of PyC to favour cartilage-like tissue neosynthesis (Garret et al., 2017; Hudek et al., 2017), the present study investigated the interaction between PyC and chondrocytes in a bone-like environment.

The effect of PyC on chondrocyte behaviour was analysed under two in vitro conditions, mimicking either bone-like conditions (as a model for the humeral surgical cavity-implant interface) or cartilage-like conditions (for the glenoid cartilageimplant interface). PyC was compared to the more commonly used CoCr biomaterial. The aim of the study was to assess the potential advantages of PyC for interposition shoulder arthroplasty, regarding the regeneration of the surrounding tissues.

\section{Materials and Methods}

\section{Biomaterials}

The samples used in the study were made of PyC and CoCr, supplied by Wright Medical Group N.V. (Grenoble, France) and sterilised in the LaMCoS research laboratory. Their surface conditions were similar to the medical implants used in shoulder arthroplasty. The samples were disk-shaped with the following dimensions: for PyC, $20 \mathrm{~mm}$ diameter, $2 \mathrm{~mm}$ thickness; for CoCr, $22 \mathrm{~mm}$ diameter, $2 \mathrm{~mm}$ thickness. The roughness ( $\mathrm{Ra}$ ) of $\mathrm{PyC}$ and $\mathrm{CoCr}$ disks was assessed by classic topography with a rugosimeter Altisurf 500 (ALTIMET, Montmélian, France): $\mathrm{Ra}_{\mathrm{PyC}}=16.9 \pm 1.9 \mathrm{~nm} ; \mathrm{Ra}_{\mathrm{CoCr}}=12.0 \pm 2.8 \mathrm{~nm}$. Culture plate wells without biomaterial (polystyrene, $35 \mathrm{~mm}$ diameter, Corning) were used as control.

\section{Chemicals and reagents}

Culture medium, foetal bovine serum (FBS), antibiotics, 3-(4,5-dimethylthiazol-2-yl-)2,5diphenyltetrazolium bromide (MTT), alizarin red, p-nitrophenyl phosphate, Nonidet P40, cetylpyridinium chloride and o-cresolphthalein complexone were purchased from Sigma-Aldrich. 
Table 1. Planning of chondrocyte culture. Amplification medium: DMEM, $10 \% \mathrm{FBS}, 1 \mathrm{~g} / \mathrm{L}$ glucose. CLC medium: DMEM, 10 \% FBS, 4.5 g/L glucose. BLC medium: DMEM, $10 \%$ FBS, 4.5 g/L glucose, 50 rg/mL ascorbic acid, $10 \mathrm{mM} \beta$-glycerophosphate.

\begin{tabular}{|c|c|c|c|}
\hline Day & Tests & CLC & BLC \\
\hline 0 & & $\begin{array}{c}\text { Dissection } \\
\text { Biomaterial hydration in PBS }\end{array}$ & $\begin{array}{c}\text { Dissection } \\
\text { Biomaterial hydration in PBS }\end{array}$ \\
\hline 1 & & Cell seeding in amplification medium & Cell seeding in amplification medium \\
\hline 3 & & Amplification medium change & Amplification medium change \\
\hline 6 & & Chang to CLC medium & Chang to CLC medium \\
\hline 7 & & CLC medium change & Chang to BLC medium \\
\hline 10 & Day 10 & \multicolumn{2}{|c|}{ Viability and toxicity tests } \\
\hline 13 & & CLC medium change & BLC medium change \\
\hline 16 & & CLC medium change & BLC medium change \\
\hline & Day 17 & \multicolumn{2}{|c|}{ Mineralisation and calcium tests } \\
\hline
\end{tabular}

\section{Murine primary chondrocytes}

Murine chondrocytes were obtained by dissection of 4-6 d old mice. Cartilage was recovered from femoral heads and knees of the hind limbs. Cells were obtained by sequential enzymatic digestions, as described by Gosset et al. (2008). Approximately 1.5 million cells per mice were obtained and seeded at a density of 12,500 cells $/ \mathrm{cm}^{2}$ in 6 -well culture plates. Before seeding, implant samples were placed in a sterilised 6-well culture plate with phosphatebuffered saline (PBS) to be hydrated overnight. Biomaterial disks did not cover the entire well of the culture plate, so that most of the seeded cells grew on the biomaterial disks but some of them grew on the underlying polystyrene.

\section{Cell culture conditions}

Chondrocytes were cultured at $37^{\circ} \mathrm{C}$ in the presence of $5 \% \mathrm{CO}_{2}$ in a saturated water atmosphere for $17 \mathrm{~d}$. The culture medium $(4 \mathrm{~mL} /$ well) was changed regularly, as shown in Table 1. First, an amplification culture medium was used: Dulbecco's modified Eagle medium (DMEM) containing $20 \mathrm{mM}$ L-glutamine, $1 \mathrm{~g} / \mathrm{L}$ glucose, $100 \mathrm{U} / \mathrm{mL}$ penicillin, $100 \mu \mathrm{g} / \mathrm{mL}$ streptomycin and $10 \%$ FBS (v/v). Then, cells were treated with two different media: DMEM supplemented with $4.5 \mathrm{~g} / \mathrm{L}$ glucose, $100 \mathrm{mM}$ 4-(2-hydroxyethyl)-1-piperazineethanesulfonic acid (HEPES), 10 \% FBS (v/v), 20 mM L-glutamine, $100 \mathrm{U} / \mathrm{mL}$ penicillin, $100 \mu \mathrm{g} / \mathrm{mL}$ streptomycin for the cartilage-like condition (CLC) or the same medium plus $50 \mu \mathrm{g} / \mathrm{mL}$ ascorbic acid and $10 \mathrm{mM}$ $\beta$-glycerophosphate for the bone-like condition (BLC). Ascorbic acid and $\beta$-glycerophosphate are two factors commonly used to enhance osteoblastic differentiation and mineralisation (Langenbach and Handschel, 2013).

\section{Viability test by MTT assay}

MTT viability test was conducted at day 10 to measure the effect of different biomaterials on chondrocytes. Briefly, MTT is transformed by living and metabolically active cells into violet formazan crystals, which can be measured after solubilisation in dimethyl sulphoxide (DMSO) at $570 \mathrm{~nm}$ (Mosmann, 1983). Cells were incubated at $37^{\circ} \mathrm{C}$ for $4 \mathrm{~h}$ with $0.125 \mathrm{mg} / \mathrm{mL}$ of MTT (final concentration). Then, the MTT-containing medium was removed and formazan crystals were solubilised using $4 \mathrm{~mL} \mathrm{DMSO/well.}$ Because biomaterial disks did not cover the entire plastic-well, they were translocated into new plates and $2 \mathrm{~mL}$ of DMSO were added on both the cells grown on the disk and those grown on the underlying plastic (control). The absorbance of cells grown on the disks indicated cell viability on the biomaterial surface and the sum of the two absorbances were compared to the control without biomaterial sample (assumed to be $100 \%$ viability).

\section{Cytotoxicity test by lactate dehydrogenase (LDH) assay}

The cytotoxicity test was carried out simultaneously with the viability test, at day 10 . Briefly, LDH is a cytosolic enzyme, which is released into the culture 
medium in any case of cell damage. Extracellular LDH was detected in $200 \mu \mathrm{L}$ of culture medium using an LDH Cytotoxicity Assay Kit (Pierce; ThermoFisher Scientific), as described by the manufacturer. The control well without biomaterial sample was used as a negative control, assumed to be $0 \%$ of cytotoxicity. In addition, a positive control $[10 \%$ Triton X-100 (v/v) added to the cells to induce full LDH release] well (without biomaterial sample) was used as a reference of $100 \%$ cytotoxicity. The results are presented in percentage of cytotoxicity as compared to the control without biomaterial.

\section{Mineralisation test by alizarin red staining}

The mineralisation test was performed at the end of the culture period, at day 17. The alizarin red dye was used to determine the presence of calcium deposits in the chondrocyte extracellular matrix, reflecting the degree of mineralisation of the matrix (Stanford et al., 1995). First, cells were washed with PBS. The biomaterial samples were translocated into another plate to take account of the cells grown on the disks and those grown on the underlying plastic. Cells were fixed by adding $2 \mathrm{~mL}$ of $70 \%$ ethanol (v/v) for $20 \mathrm{~min}$ at room temperature and washed with pure water for $5 \mathrm{~min}$. Then, the plates were incubated for $20 \mathrm{~min}$ at room temperature with $2 \mathrm{~mL} /$ well of $2 \%(\mathrm{v} / \mathrm{v})$ alizarin red, $\mathrm{pH}$ 4.2. After 3 washes with water, $2 \mathrm{~mL} /$ well of $100 \mathrm{mM}$ cetylpyridinium chloride were added to solubilise the alizarin red. Following an overnight incubation under gentle stirring at room temperature, absorbance was measured at $570 \mathrm{~nm}$. The results are presented as a percentage of mineralisation in comparison to the control (100\% mineralisation).

\section{Specific calcium deposition assay}

To complete the mineralisation test by alizarin red staining, calcium deposits in the extracellular matrix were quantified at day 17. Deposited calcium was extracted from the extracellular matrix using $0.6 \mathrm{M}$ $\mathrm{HCl}$ and kept overnight at room temperature. The calcium content of the $\mathrm{HCl}$ supernatant was dosed by a colorimetric assay using the o-cresolphthalein complexone method (Sigma-Aldrich) (Moorehead and Biggs, 1974). Briefly, $2 \mathrm{~mL}$ of $0.6 \mathrm{M} \mathrm{HCl} /$ well were used to extract calcium and $20 \mu \mathrm{L}$ of samples were mixed with $100 \mu \mathrm{L}$ of reagent. The absorbance was measured at $570 \mathrm{~nm}$ after plate incubation for $5 \mathrm{~min}$ at room temperature. Calcium quantities were standardised by the protein content. Bicinchoninic acid protein assay was performed using the Pierce BCA Protein Assay kit (ThermoFisher Scientific), as described by the manufacturer.

\section{Tissue non-specific alkaline phosphatase (TNAP) assay}

TNAP activity is used as an indicator of mineralising cells. TNAP activity measurement is based on the cleavage of the synthetic substrate paranitrophenylphosphate into a yellow compound, the para-nitrophenol (Cyboron and Wuthier, 1981). Briefly, $400 \mu \mathrm{L} /$ well of $0.2 \%$ Nonidet P40 (v/v) were added and $20 \mathrm{~s}$ of sonication were used to extract TNAP from the cells. $20 \mu \mathrm{L}$ of samples were mixed with $180 \mu \mathrm{L}$ of the reagent, as described by Cyboron and Wuthier (1981). The absorbance was measured kinetically at $405 \mathrm{~nm}$ for $5 \mathrm{~min}$ at $37^{\circ} \mathrm{C}$. BCA protein assay was performed to calculated TNAP specific activity. Results were calculated as $\mu \mathrm{mol}$ of paranitrophenol ( $\mathrm{pNP}$ ) produced $/ \mathrm{min} / \mathrm{mg}$ protein and normalised relative to their respective controls.

\section{Histological staining}

At day 17 of culture, tissue-like cell membrane formed with chondrocytes were removed carefully from the biomaterial surfaces for histological analyses. Tissue-like cell membranes were fixed in $4 \%(\mathrm{v} / \mathrm{v})$ formalin, embedded in paraffin, sectioned into $5 \mu \mathrm{m}$ thick sections using a microtome and mounted with an albumin-glycerol mixture on untreated slides. For haematoxylin-eosin-saffron (HES) staining, after dewaxing, sections were immersed successively in solutions of Harris haematoxylin, eosin and saffron (Edston and Gröntoft, 1997). Cytoplasm is stained pink, nucleus violet-blue and extracellular matrix from yellow to pink. For von Kossa staining, after fixation in $4 \%$ formalin (v/v) for 15 min and 2 washes with distilled water, samples were incubated with $5 \%$ silver nitrate $(\mathrm{w} / \mathrm{v})$ solution for $30 \mathrm{~min}$ under ultraviolet light then rinsed 3 times with distilled water. Results were observed after complete drying, with black granulations being indicative of

Table 2. Semi-quantitative evaluation of histological and immunohistological analyses.

\begin{tabular}{|c|c|c|}
\hline Score & $\begin{array}{c}\text { Chondrocyte clustering (HES staining) and } \\
\text { mineralisation areas (von Kossa staining) }\end{array}$ & $\begin{array}{c}\text { Collagen I, collagen II and aggrecan labelling } \\
\text { (matricial and cellular) }\end{array}$ \\
\hline 0 & No cluster/no mineralisation & Slight specific staining/labelling ( $\leq 10 \%)$ \\
\hline 1 & Few cluster/few mineralised areas $(\leq 10 \%)$ & Moderate specific staining/labelling $(10-50 \%)$ \\
\hline 2 & $\begin{array}{c}\text { Moderate number of clusters/mineralised areas } \\
(10-50 \%)\end{array}$ & Strong specific staining/labelling $(\geq 50 \%)$ \\
\hline 3 & Numerous clusters/mineralised areas $(\geq 50 \%)$ & \\
\hline
\end{tabular}


mineralised zones. After dehydration, sections were mounted between slide and cover slip using Entellan ${ }^{\circledR}$ (Sigma-Aldrich). A Leica DM2000 light microscope was used for microscopic observations. Images were taken with a LAS Version 4 digital camera (Leica) at different magnifications and edited using the imageprocessing software Adobe Photoshop CC2015.5.

\section{Immunolabelling}

Different immunolabellings were performed for collagen type I, collagen type II and aggrecan. Tissue-like cell membrane sections were obtained as previously described and glued onto treated slides (superfrost plus glass slides are made by a process which electrostatically attracts fresh-frozen and formalin-fixed paraffin-embedded tissue section, binding them to the slide. Hémato Mayer: Diapath C0303, MMFrance, Brignais, France). After dewaxing, antigenic site retrieval was carried out using $0.5 \%$ hyaluronidase solution (clone H3506, Sigma-Aldrich) for matrix labelling. After incubation in the respective antibody solutions overnight at $4{ }^{\circ} \mathrm{C}$ (Novotec, 20111, 20211 and 24411), endogenous activity was blocked with $0.5 \%$ hydrogen peroxide. After incubation with peroxidase-labelled rabbit HRP EnVision antibody (K4002, Dako), antigen-antibody complexes were revealed by tetrahydrochloride diaminobenzidine (DAB, K3468, Dako) and sections were slightly counterstained with Mayer's haematoxylin (Edston and Gröntoft, 1997). Negative controls were carried out with PBS. A Leica DM2000 light microscope was used for microscopic observations. Pictures were taken with a LAS Version 4 digital camera and edited using the image-processing software Adobe Photoshop CC2015.5.

a

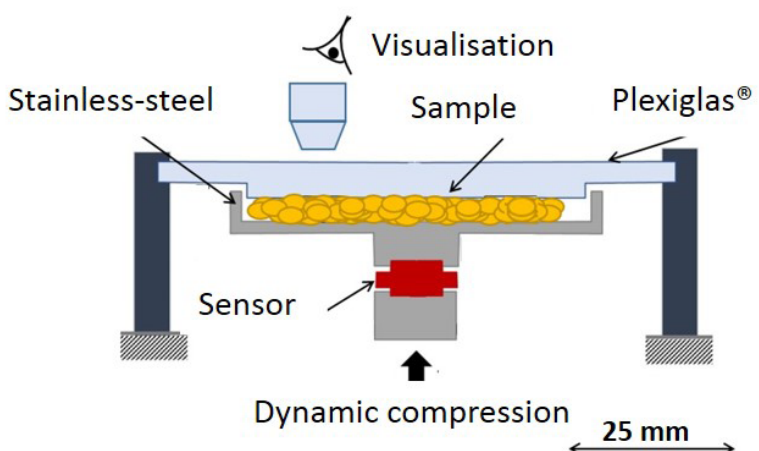

\section{Semi-quantitative histological and immunohistological analyses}

Each tissue-like cell membrane was observed at a $40 \times$ magnification and each parameter was evaluated by a semi-quantitative approach. The histological scoring was based on the number of chondrocyte clusters, the percentage of staining areas when compared to the total surface and/or the density of the immunolabelling (Table 2).

\section{Hand-made device for rheological tests}

Instead of using a classic rheometer, a new device developed by the LaMCoS research laboratory, 'tribo-bioreactor', was used for the rheological tests (Fig. 1a). Two parallel circular trays composed the 'tribo-bioreactor': a Plexiglas ${ }^{\circledR}$ tray, which facilitated the sample visualisation during the mechanical test, and a stainless-steel tray, which facilitated the mechanical stress application. The gap between the two trays was a controlled parameter due to the mobility of the stainless-steel tray, which was clamped to a lifting table. The 'tribo-bioreactor' allowed for the application of both compression and shear (simultaneously or separately) to a sample placed between its trays. A LabVIEW interface (National Instruments, Nanterre, France) was developed to monitor the device and to adjust the needed load: type (compression or shear), value and frequency. The mechanical stress was obtained by the displacements of piezoelectric actuators (Amplified Piezo Actuators, Cedrat Technologies, Grenoble, France): a vertical displacement for the compression and a horizontal displacement transformed into rotation by an elastic system for the shear. The two displacements were measured by strain gauges.

b

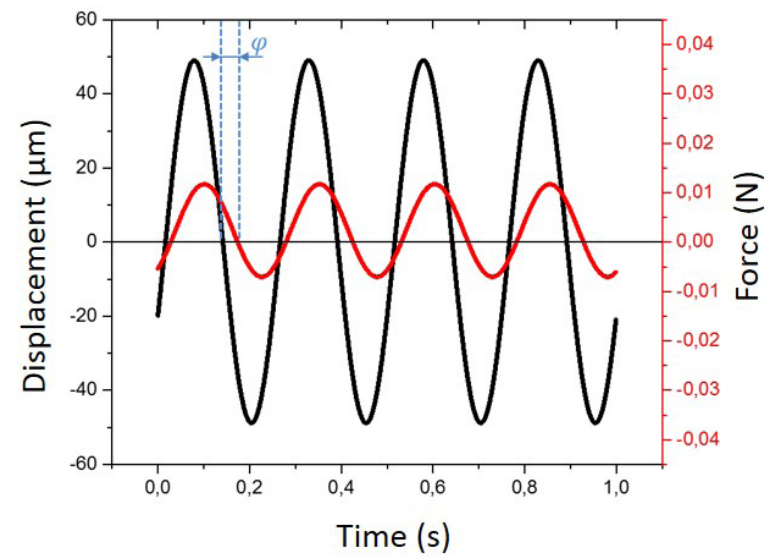

Fig. 1. Rheological test method. (a) Diagram illustrating the hand-made 'tribo-bioreactor' that was used for the rheological tests. The sample, which is represented as a tissue-like cell membrane, was placed between the two trays. The top tray is in Plexiglas ${ }^{\circledR}$ and allows for visualisation, the bottom tray is in stainless-steel and allows for application of the dynamic force. The sensor allows measuring the normal force produced by the sample. (b) Signals obtained from the DMA using the hand-made 'tribo-bioreactor'. Sinusoidal displacement of the stainless-steel tray is drawn in black and normal force obtained in response is drawn in red. $\varphi$ indicates the phase shift between the two signals, which allows the calculation of complex modulus $\left(G^{*}\right)$, elastic modulus $\left(G^{\prime}\right)$, viscous modulus $\left(G^{\prime \prime}\right)$ and viscosity $(\eta)$. 
The force and the torque were measured by a piezoelectric sensor (KISTLER, Les Ulis, France) with a 2-Component Force Reaction Torque Link. This sensor allows measuring the dynamic normal force needed to evaluate the mechanical proprieties of the samples.

\section{Tissue mechanical characterisation}

The rheological test performed using the 'tribobioreactor' was an application of dynamic compression to the sample placed between its two trays, which represented a dynamic mechanical analysis (DMA, Fig. 1b). The DMA is a non-destructive technique to characterise the viscoelastic properties of different samples (Jones, 1999). These proprieties can be studied by imposing a sinusoidal stress or a deformation. This use of the 'tribo-reactor' was validated by a comparison with the measurements obtained by a classic rheometer.

The stress $(\sigma)$ and strain $(\varepsilon)$ in DMA are mathematically described by the following equations:

$$
\begin{gathered}
\sigma(t)=\sigma_{0} \cos (2 * \pi * f * t+\varphi) \\
\varepsilon(t)=\varepsilon_{0} \cos (\omega t)
\end{gathered}
$$

where $\sigma_{0}$ and $\varepsilon_{0}$ represent the stress and strain, $\varphi$ the phase shift between the two signals, $\omega$ is the pulsation and $f$ the frequency. For the rheological test, the 'tribo-reactor' only allowed the measurement of the displacement and force. That is why it was necessary to calculate $\sigma_{0}$ and $\varepsilon_{0}$ to apply the DMA. The following equations

$$
\begin{gathered}
\varepsilon_{0}=\frac{A_{\text {displacement }}}{\text { gap }} \\
\sigma_{0}=\frac{A_{\text {force }}}{S}
\end{gathered}
$$

were applied, with $A_{\text {displacement }}$ representing the vertical measured displacement, $A_{\text {force }}$ the normal measured force and $S$ the contact area between the sample and the tray. The previous signals allowed calculation of the complex modulus $\left(G^{*}\right)$ of the samples and, thus, the elastic modulus $\left(G^{\prime}\right)$, the viscous modulus $\left(G^{\prime \prime}\right)$ and the viscosity $\left(n_{0}\right)$ as follows:

$$
\begin{gathered}
G^{*}=\frac{\sigma_{0}}{\varepsilon_{0}} \cos \varphi+i \frac{\sigma_{0}}{\varepsilon_{0}} \sin \varphi=G^{\prime}+i G^{\prime \prime} \\
G^{\prime}=\frac{\sigma_{0}}{\varepsilon_{0}} \cos \varphi \\
G^{\prime \prime}=\frac{\sigma_{0}}{\varepsilon_{0}} \sin \varphi \\
\mathrm{n}_{\boldsymbol{b}}=\frac{G^{\prime \prime}}{\omega}
\end{gathered}
$$

At the end of the cell culture period, each biomaterial was recovered along with the tissue-like cell membrane. The viscoelastic properties of these membranes were evaluated by rheological test. The gap between the two trays was fixed according to the volume of the cell membranes obtained for each manipulation (between 500 and $700 \mu \mathrm{m}$ ). Then, a dynamic displacement $(100 \mu \mathrm{m}, 2$ or $4 \mathrm{~Hz})$ was applied. For each sample, two signals were obtained for the applied displacement and the measured force (Fig. 1b). The complex modulus $G^{*}$ was calculated as described previously.

\section{Statistical analysis}

The results of different biological tests were analysed using the software Prism (GraphPad). Bars represent the mean and standard error of the mean (SEM) of at least 3 independent experiments (the exact number of experiments is indicated in the figure legend). Effects of the different biomaterials on the cells were compared to controls, using the Student's t-test. Results in Table 3 are presented as mean \pm standard deviation (SD). Significant results are represented as ${ }^{*} p<0.05,{ }^{* *} p<0.01$ and ${ }^{* * *} p<0.001$. Non-significant results are represented as ${ }^{\text {ns }} p>0.05$.

\section{Results}

\section{Validation of the cell culture in CLC or BLC}

Primary mouse chondrocytes were cultured for $17 \mathrm{~d}$ in CLC medium, in medium complemented with ascorbic acid (intermediate) or in BLC medium containing both ascorbic acid and $\beta$-glycerophosphate. Cells grown over the $17 \mathrm{~d}$-long culture period in CLC retained their chondrogenic phenotype. Cells were amplified without passage to avoid de-differentiation (Gouttenoire et al., 2010). As already described for chicken primary chondrocytes (Leboy et al., 1992), the addition of ascorbic acid was sufficient to promote alkaline phosphatase activity in the mouse primary chondrocyte model (Fig. 2a) and further addition of $\beta$-glycerophosphate drastically increased mineralisation, as visualised by alizarin red staining (Fig. 2b). Therefore, on the one hand, ascorbic acid was not used in the CLC medium, one the other hand, it was confirmed that the cells cultured $17 \mathrm{~d}$ in BLC differentiated into bone-forming cells. Cartilage markers such as aggrecan and type II collagen were expressed by the chondrocytes in both conditions, as detailed in following paragraphs.

\section{Chondrocytes did grow on $\mathrm{PyC}$ and $\mathrm{CoCr}$ without alteration of cell viability}

Murine chondrocytes were cultured on disks made of PyC, CoCr or without biomaterial on plastic culture plates. First, MTT test was used to assess cell viability in the presence of the biomaterials as compared to the control condition without biomaterial. The overall cell population was equivalent for PyC or CoCr disks and for the control wells (Fig. 3a). In 
correlation, less than $5 \%$ of cytotoxicity, which is negligible, was detected by the LDH cytotoxicity assay with the tested biomaterials (Fig. 3b). Thus, the contact with $\mathrm{PyC}$ or $\mathrm{CoCr}$ did not alter cell viability. Then, whether the cells adhered to the biomaterial surfaces was verified. In fact, an MTT-induced purple colour (formazan crystals) was noticeable at the surface of the disks, indicating that a cell membrane had developed on the biomaterial (Fig. 3c). MTT quantification demonstrated the viability and the attachment of the cells to the different biomaterials
(Fig. 3d). Absorbance scores were normalised to the disk area to compare cell adherence on $\mathrm{PyC}, \mathrm{CoCr}$ and plastic surfaces. Both crude observation of the picture and MTT analysis showed that chondrocytes adhered to the PyC surface as well as plastic control, whereas cell adherence to the CoCr surface was slightly lower (Fig. 3c,d). The poorer cell attachment to $\mathrm{CoCr}(-28 \%)$ might be explained by the surface chemistry of this biomaterial and its lower roughness as compared to PyC ( $-35 \%$, as indicated in Materials and Methods). a

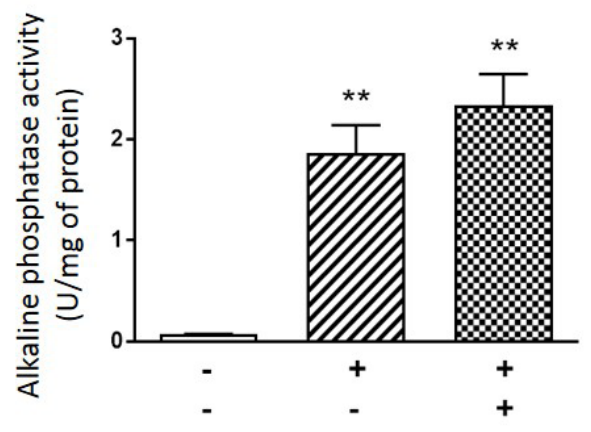

b

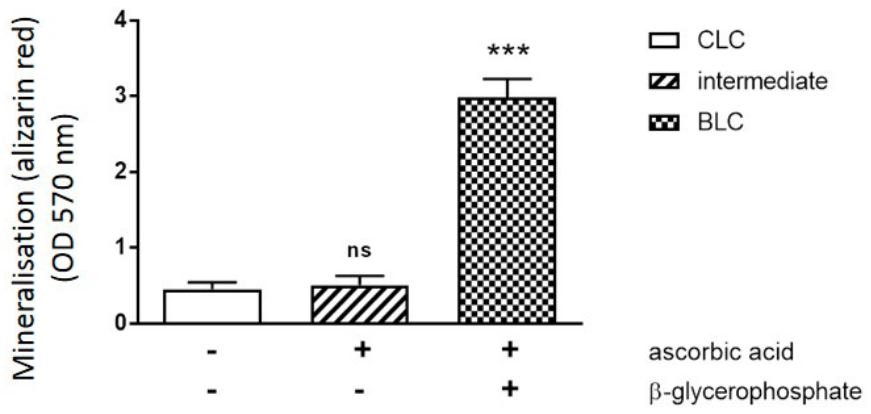

Fig. 2. Validation of the cell culture in CLC or BLC. Primary mouse chondrocytes were cultured for $17 \mathrm{~d}$ in CLC medium, in medium complemented with ascorbic acid (intermediate) or in BLC medium containing both ascorbic acid and $\beta$-glycerophosphate. (a) TNAP specific enzymatic activity was measured in cell lysate; (b) mineralisation of the extracellular matrix was assessed by staining with alizarin red. Bars indicate mean \pm SEM of 4 independent experiments. ${ }^{* *} p<0.01,{ }^{* * *} p<0.001$, ns: no statistical difference, OD: optical density.

a

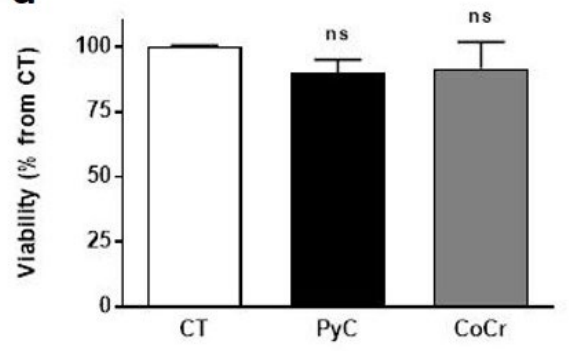

C

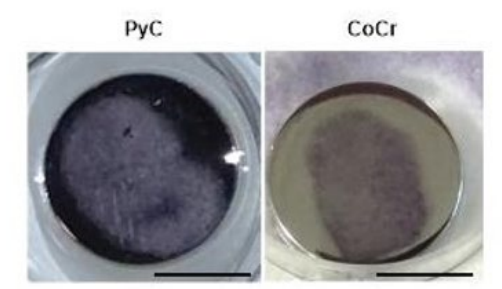

\section{b}

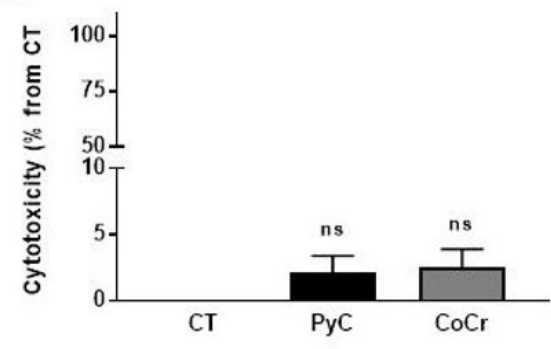

d

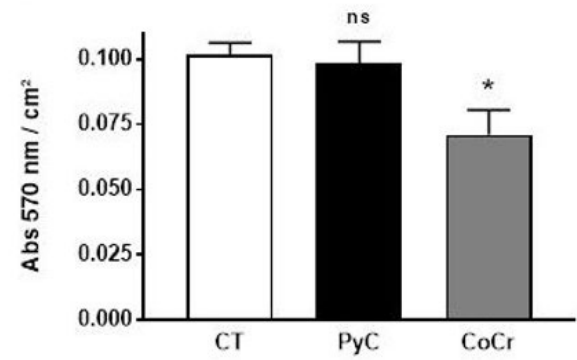

Fig. 3. Growth of chondrocytes onto PyC and CoCr without significant alteration of cell viability. Cell viability was measured by (a) MTT assay and (b) biomaterial cytotoxicity by LDH assay and compared with plastic control (CT). (c) Pictures of MTT-stained tissue-like cell membranes grown on the biomaterials (scale bars: $10 \mathrm{~mm}$ ). (d) MTT assay absorbance measured at $570 \mathrm{~nm}$ showing the attachment of the cells to the different biomaterials. Bars indicate mean \pm SEM of 4 independent experiments. ${ }^{*} p<0.05$, ns: no statistical difference. 
a

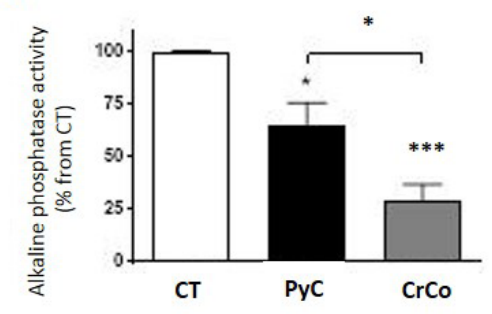

b

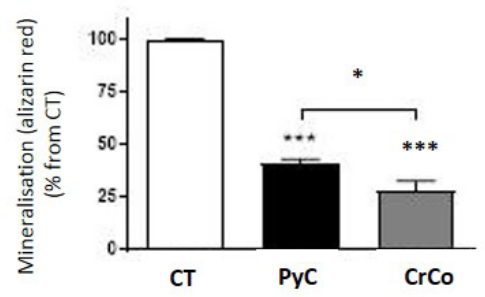

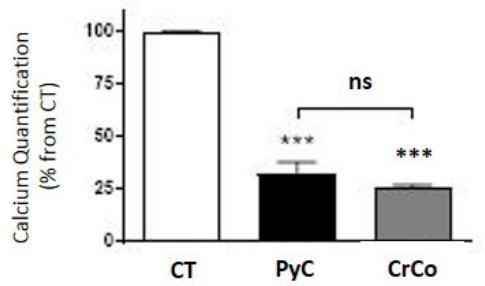

Fig. 4. Mineralisation capacity of chondrocytes grown on PyC and CoCr. (a) TNAP enzymatic activity was measured in cell lysate at the end of the culture period under BLC (day 17). (b) Mineralisation was assessed by staining with alizarin red; (c) calcium crystals deposition was directly quantified. Bars indicate mean \pm SEM of 4 or 5 independent experiments. ${ }^{*} p<0.05,{ }^{* * *} p<0.001$, ns: no statistical difference.

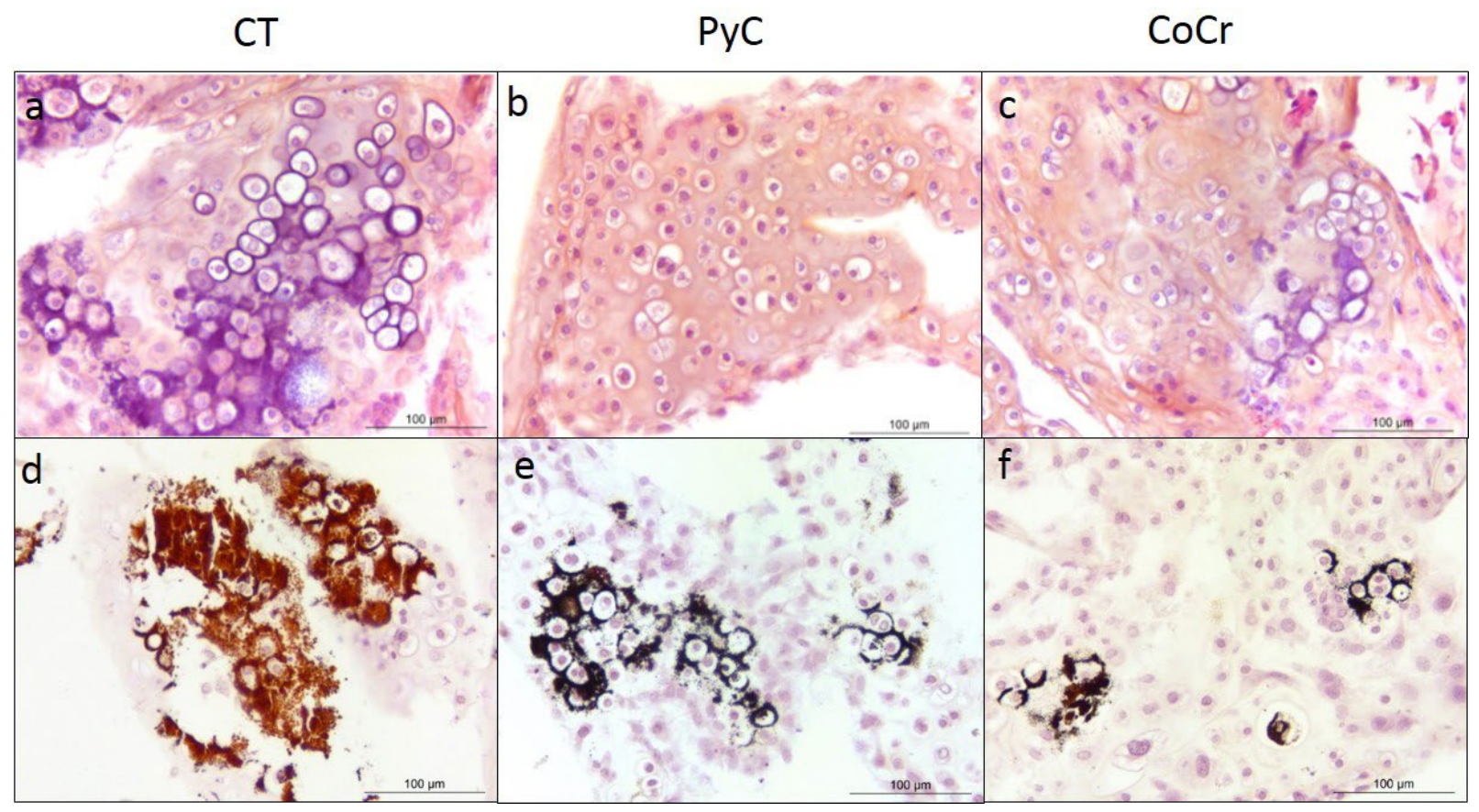

Fig. 5. Histological analysis of chondrocytes cultured under BLC. (a-c) HES and (d-f) von Kossa staining were performed on the tissue-like cell membranes grown on $(\mathbf{a}, \mathbf{d})$ plastic control, $(\mathbf{b}, \mathbf{e}) \mathrm{PyC}$ or $(\mathbf{c}, \mathbf{f}) \mathrm{CoCr}$ disks. Scale bars: $100 \mu \mathrm{m}$.

PyC promoted the creation of a homogenous tissuelike cell membrane of chondrocytes under BLC First, tests were conducted to evaluate the mineralisation capacity of cultured chondrocytes under BLC. Secondly, the extracellular matrix biological components of these tissue-like cell membranes were analysed histologically. Finally, the mechanical properties of the tissue-like cell membrane developed on the biomaterial surfaces were evaluated. All analyses were performed at the end of the culture period $(17 \mathrm{~d})$.

\section{Biomaterials affected the mineralisation capacity} of the cultured chondrocytes

TNAP is an enzyme necessary for mineralisation of the extracellular matrix and it is present in calcified tissues (Balcerzak et al., 2003). An important TNAP activity, which can be measured in the cell lysate, reflects usually a high rate of mineralisation
(Balcerzak et al., 2003; Fakhry et al., 2017). A significant decrease of this enzymatic activity in cultured chondrocytes was observed on both PyC and $\mathrm{CoCr}$, in comparison to the plastic control (Fig. 4a). However, TNAP activity was significantly higher in cells grown on PyC than on CoCr (2.2-fold). Then, alizarin red staining was performed to distinguish calcium crystals from the extracellular matrix. A staining diminution of around $60 \%$ was observed in the presence of both biomaterials as compared to the plastic control (Fig. 4b). Concurrently, mineralisation was significantly greater in the presence of PyC than in the presence of $\mathrm{CoCr}$ (1.4-fold), which corroborated the analysis of TNAP activity. As expected, the quantitative measurement of the specific calcium deposition correlated with the results obtained with the alizarin red staining. For both biomaterials, a reduction of about $60 \%$ was observed by comparison with the plastic control (Fig. 4c). However, the 
Table 3. DMA analysis of chondrocytes cultured under BLC on PyC or CoCr.

\begin{tabular}{|l|c|c|c|c|}
\hline & \multicolumn{2}{|c|}{ Cell membranes on CoCr } & \multicolumn{2}{c|}{ Cell membranes on PyC } \\
\hline Frequency of displacement & $2 \mathrm{~Hz}$ & $4 \mathrm{~Hz}$ & $2 \mathrm{~Hz}$ & $4 \mathrm{~Hz}$ \\
\hline Elasticity $G^{\prime}\left(\mathrm{N} / \mathrm{m}^{*} \mathrm{~m}\right)$ & $1024 \pm 399$ & $1092 \pm 411$ & $1822 \pm 722$ & $1880 \pm 660$ \\
\hline Viscosity $\eta_{0}(\mathrm{~Pa} \times \mathrm{s})$ & $185 \pm 116$ & $115 \pm 100$ & $170 \pm 94$ & $86 \pm 47$ \\
\hline
\end{tabular}

difference between PyC and $\mathrm{CoCr}$ was not significant in this case.

Histological analysis of the extracellular matrix biological components of the tissue-like cell membranes

Histological analysis was performed on the tissuelike cell membranes developed on the biomaterial surfaces under BLC. HES staining revealed tissue-like cell membranes organisation with large amount of extracellular matrix connecting the cells (Fig. 5a-c). The overall structure showed small differences between control and both $\mathrm{PyC}$ and $\mathrm{CoCr}$. Chondrocytes grown on plastic control under BLC had heterogeneous size and morphology. Globally, cells exhibited a round shape and a voluminous nucleus (Fig. 5a). The morphology of the cells grown on PyC was more homogeneous, whereas cells grown on $\mathrm{CoCr}$ were very similar to the control sample (Fig. $5 \mathbf{b}, \mathbf{c}$ ). Many cell clusters were observed independently of the support. Particularly, numerous clustered hypertrophic chondrocytes were noticed, which were recognisable because of their large diameter (Fig. 5a-c). Matrix mineralisation was analysed by von Kossa staining of the histological sections (Fig. 5d-f). This analysis confirmed the in vitro assays (alizarin red staining, specific calcium deposition assay and TNAP assay): more mineralised zones were detected in tissue-like cell membrane grown on plastic control than on both biomaterials and more on the $\mathrm{PyC}$ disks than on the $\mathrm{CoCr}$ disks. Overall, under BLC, the tissue-like cell membranes grown on $\mathrm{PyC}$ were more mineralised and more homogenous than those grown on $\mathrm{CoCr}$.

The biomaterials affected the mechanical proprieties of the tissue-like cell membranes

The tissue-like cell membranes developed on $\mathrm{PyC}$ and $\mathrm{CoCr}$ surfaces were placed into the hand-made 'tribo-bioreactor' for DMA. For each sample, the complex modulus $G^{*}$ was calculated twice, with a displacement's frequency of 2 and $4 \mathrm{~Hz}$. Three independent experiments were performed and the calculation of the elastic modulus $G^{\prime}$ gave acceptable accuracy and reproducible results (Table 3). However, the values of viscous modulus $G^{\prime \prime}$ and, thus, of viscosity $\eta_{0}$ were very variable (Table 3 ), so that no difference was observed between $\mathrm{PyC}$ and $\mathrm{CoCr}$ in terms of viscosity. For a better standardisation, results were paired: data obtained with tissue-like cell membranes grown on PyC were compared to chondrocytes cultured on $\mathrm{CoCr}$ in the same medium condition (Fig. 6). The elastic modulus $G^{\prime}$ of the tissue-like cell membranes grown on PyC was $1.8 \pm 0.3$-fold higher than the one on $\mathrm{CoCr}$ (both at 2 and $4 \mathrm{~Hz} ; p=0.046$ and $p=0.052$, respectively; $n=3$; Fig. 6). Therefore, as expected, the DMA corroborated the previously observed differential mechanical properties of chondrocytes cultured under BLC on $\mathrm{PyC}$ or $\mathrm{CoCr}$ disks. Indeed, in the presence of $\mathrm{PyC}$, the tissue-like cell membrane samples were more elastic or more resistant than in the presence of $\mathrm{CoCr}$.

Extracellular matrix biological components of the tissue-like cell membranes

To characterise the biological components of the extracellular matrix of each tissue-like cell membrane, immunolabellings were performed to detect type I and type II collagen and aggrecan (Fig. 7). Type II collagen and glycosaminoglycans attached to aggrecan protein are the major components of cartilage extracellular matrix, whereas type I collagen is absent in healthy cartilage, but present in other body tissues, especially healing tissues (Hoemann et al., 2012). Type I collagen was used as a marker of bone-like extracellular matrix. Immunohistological analysis confirmed the tissue-like cell membrane organisation that was suggested by HES staining observations (Fig. 5). The chondrocytes grown on plastic control under BLC generated a homogeneous extracellular matrix, with various amounts of type I and type II collagens and aggrecan (Fig. 7a,d,, $\mathbf{g}$ ). Overall, the matrix of the tissue-like cell membranes grown on both PyC and $\mathrm{CoCr}$ seemed more heterogeneous. However, all the studied markers were detected in large

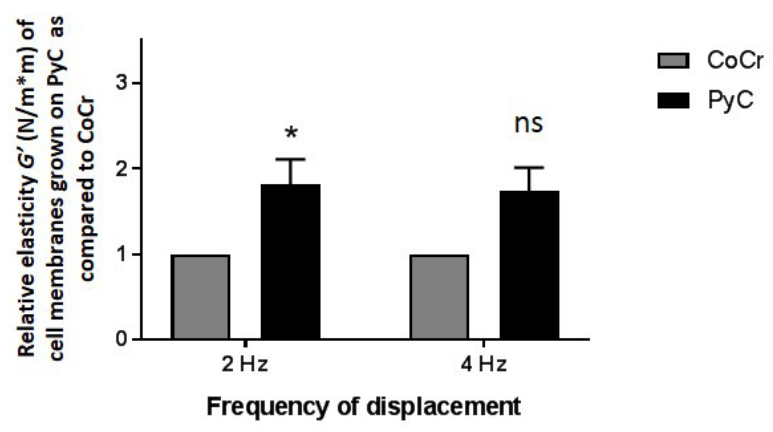

Fig. 6. Mechanical properties of chondrocytes cultured under BLC on PyC or CoCr. Rheological tests were performed with the 'tribo-bioreactor' on tissue-like cell membranes and the elastic modulus $\left(G^{\prime}\right)$ was calculated. The elasticity of the PyC samples was compared with chondrocytes cultured on $\mathrm{CoCr} .{ }^{*} p<0.05$, ns: no statistical difference. 


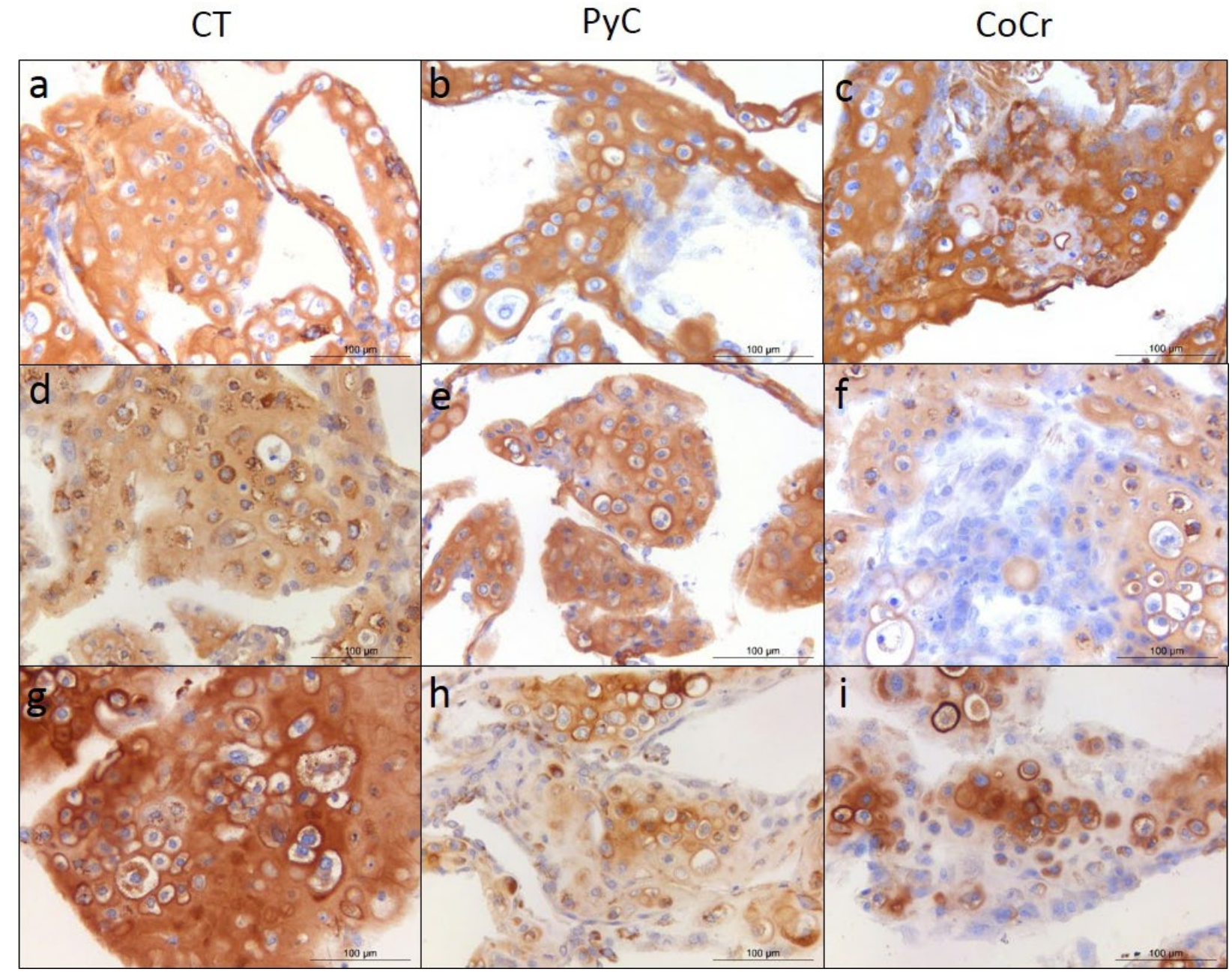

Fig. 7. Matrix biological components of the tissue-like cell membranes grown under BLC. Immunolabelling for $(\mathbf{a}-\mathbf{c})$ type I collagen, $(\mathbf{d}-\mathbf{f})$ type II collagen and (g-i) aggrecan was performed on the tissue-like cell membranes grown on $(\mathbf{a}, \mathbf{d}, \mathbf{g})$ plastic control, $(\mathbf{b}, \mathbf{e}, \mathbf{h})$ PyC or $(\mathbf{c}, \mathbf{f}, \mathbf{i})$ CoCr. Scale bars: $100 \mu \mathrm{m}$.

amounts, suggesting that matrix compositions were very similar (Fig. 7). The only difference detected between the two biomaterials was noticed for the immunolabelling of type II collagen, which was more obvious on tissue-like cell membranes grown on PyC surface than on CoCr surface (Fig. 7e,f). Overall, under BLC, the chondrocytes grown on PyC generated a dense extracellular matrix, which contained cartilage-specific components but also type I collagen.

PyC might promote a more cartilage-like matrix membrane from chondrocytes cultured under CLC Histological analysis of tissue-like cell membranes was performed at the end of the culture period (17 d). HES staining revealed that the overall tissue-like cell membrane organisation was very similar between plastic control and both biomaterials (Fig. 8a-c). The chondrocytes grown under CLC had heterogeneous size and morphology and were often arranged in clusters (Table 4). No mineralisation zones and fewer clusters of hypertrophic chondrocytes were noticed under CLC than under BLC, thus confirming that CLC did not promote differentiation into bone- forming cells (Fig. 7,8). Because in CLC cells were grown without ascorbic acid, which is essential for the stabilisation of the extracellular collagen fibres (Leboy et al., 1992), the analysis of the extracellular matrix staining should be performed with caution. However, the extracellular matrix of the tissuelike cell membranes grown on plastic control was characterised by the presence of type I collagen (Fig. 8d) and aggrecan (particularly in the pericellular zone) (Fig. 8j). CoCr samples were very similar to the control condition (Table 4, Fig. 8a vs. c, d vs. f, g vs. i, j vs. 1). For PyC samples, immunolabelling of the matrix aggrecan seemed comparable to control (Fig. 8j vs. k) but type I collagen labelling appeared less strong (Fig. 8e) than in control (Fig. 8d). In the absence of ascorbic acid, collagens tend to build up intracellularly (Langenbach and Handschel, 2013), therefore, type II collagen was weakly detected in the matrix but more visible intracellularly (Fig. 8h) when compared to control (Fig. 8g). Outstandingly, more chondrocytes were positive for type II collagen in PyC samples, thus demonstrating that ongoing synthesis of type II collagen was higher than in the control condition (Fig. $8 \mathbf{g}, \mathbf{h}$ ). In contrast, a small 


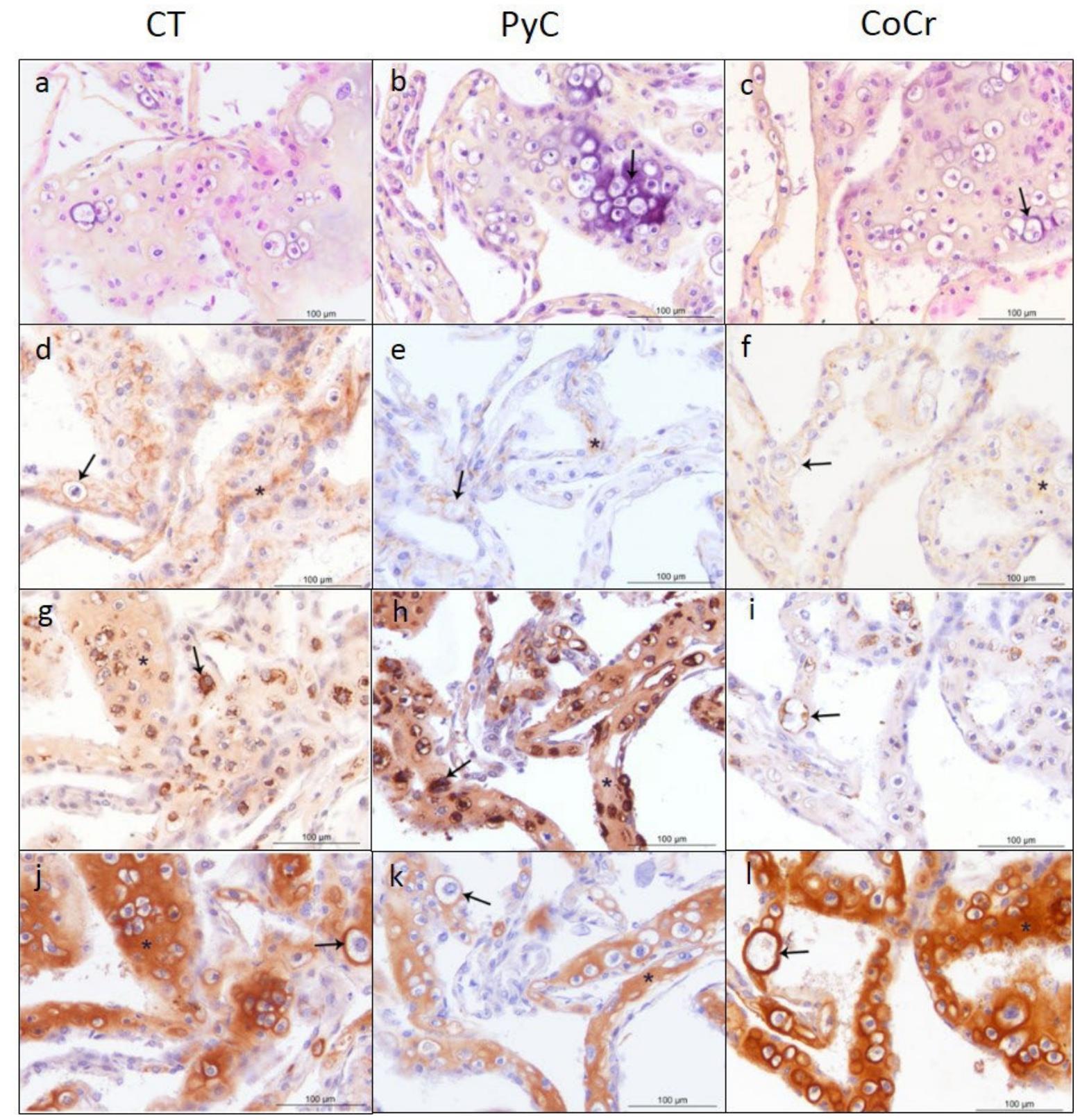

Fig. 8. Immunohistological analyses of chondrocytes cultured under CLC. (a-c) HES staining was performed on the tissue-like cell membranes grown on (a) plastic control, (b) PyC or (c) CoCr. Immunolabelling for (df) type I collagen, (g-i) type II collagen and (j-1) aggrecan was performed on the tissue-like cell membranes grown on $(\mathbf{d}, \mathbf{g}, \mathbf{j})$ plastic control, $(\mathbf{e}, \mathbf{h}, \mathbf{k})$ PyC or $(\mathbf{f}, \mathbf{i}, \mathbf{l})$ CoCr. Arrows indicate hypertrophic chondrocytes and asterisks indicate zones with high specific staining. Scale bars: $100 \mu \mathrm{m}$.

amount of type II collagen was detected within the cells grown on CoCr (Fig. 8i). To summarise, histological analysis showed that the chondrocytes grown on PyC surface under CLC should be able to generate a more cartilage-like matrix than both $\mathrm{CoCr}$ and plastic control samples, in particular by producing more type II collagen.

\section{Discussion}

Different approaches can be considered for investigating biological response to joint prosthesis.
For the conventional TSA and RSA procedures, one of the main challenges is the skeletal embedding of the implant. Most studies on arthroplasty procedures look for bone growth (osseointegration), stimulation of osteogenesis (osteoinduction) and increased vascularisation in the surrounding bone tissue since improved mechanical stability would increase long-term clinical outcomes (Lewallen et al., 2014). However, the design of the spherical interposition implants allows overriding this problem. Another part of the investigation concerns improvement of joint prosthesis by using superior biomaterials. The aim is to minimise the stress shielding effect and the 
Table 4. Histological analysis of chondrocytes cultured under CLC on plastic, PyC or CoCr. Semi-quantitative scoring according to Table $2 .{ }^{a}$ indicates a difference in comparison to plastic control. ${ }^{b}$ indicates a difference between PyC and CoCr.

\begin{tabular}{|l|c|c|c|}
\hline & Control cell membranes & Cell membranes on PyC & Cell membranes on CoCr \\
\hline Chondrocytes clusters & 2 & 2 & 2 \\
\hline Collagen type I & 1 & $0^{\mathrm{a}, \mathrm{b}}$ & $1^{\mathrm{b}}$ \\
\hline Collagen type II & 2 & $3^{\mathrm{a}, \mathrm{b}}$ & $1^{\mathrm{a}, \mathrm{b}}$ \\
\hline Aggrecan & 3 & $2^{\mathrm{a}, \mathrm{b}}$ & $3^{\mathrm{b}}$ \\
\hline
\end{tabular}

shear stress between the implant and the surrounding tissue. Concerning this point, the tribological interest in PyC is already demonstrated (Cook et al., 1989; Cook et al., 1999). Finally, a smaller group of studies investigate in vitro the cellular response to the contact with the implant biomaterial (Behzadi et al., 2012; Goodman et al., 1996). The present study belonged to this group and the experiments were designed to analyse the effect of $\mathrm{PyC}$ on the behaviour of the chondrocyte coming in contact with it and to compare it with the more commonly used $\mathrm{CoCr}$.

As a model, primary chondrocytes were cultured directly on PyC or CoCr surfaces or on plastic control. In a spherical implant for shoulder arthroplasty, the implant opposes the glenoid and, thus, a source of chondrocytes. However, immediate adhesion of chondrocytes to the implant surface is not yet confirmed. Direct interaction between cartilage cells and PyC might be more prominent in the case of patients with osteoarthritic pathologies, where the superficial cartilage is damaged at the time of the implantation, than in the case of patients with healthy glenoid. On the other side, the implant is facing the humeral bone cavity, containing a mix of mesenchymal stem cells, cartilage and bone cells. The contribution of each cell-type to the tissueregeneration process is still undefined. The present study focused on chondrocytes but stem cells may well have a preponderant role in situ. Besides, the presented model allowed for the investigation of chondrocyte behaviour in a static environment. However, skeletal cells, including chondrocytes, are mechanosensitive and could react to the tribological stress caused by the non-fixed prosthesis and its spherical shape. For all these limitations, it was only possible to speculate on the potential translation of the in vitro results into clinical outcomes.

The results of MTT and LDH tests showed no alteration of cell viability or cytotoxicity in the cell culture model. Thus, PyC and $\mathrm{CoCr}$ appeared to be innocuous biomaterials for chondrocytes. This result was expected because both biomaterials are already used for medical applications. In particular, PyC has been used for more than 3 million implantations of heart valves (Cook et al., 1999; Goodman et al., 1996). Also, cell adherence was higher on the PyC surface than on the $\mathrm{CoCr}$ surface. How cells attach to the biomaterial highly depends on the biomaterial surface proprieties and on which molecules can adsorb on it (Anselme, 2000; Gittens et al., 2014). The present study results proved that surface chemistry and roughness of the biomaterials are important parameters for cell behaviour in general and particularly for chondrocytes, which can discriminate between the subtle surfaces differences (Boyan et al., 1996; Gittens et al., 2014).

The effect of PyC was analysed on chondrocyte behaviour under BLC, as a model for the humeral surgical cavity-implant interface. The osteogenic potential of the BLC medium was validated in the plastic control. As expected, cultured chondrocytes developed a mineralised extracellular matrix and several hypertrophic chondrocytes were also detected. They produced large amounts of extracellular matrix forming tissue-like cell membranes with mixed characteristics of bone and cartilage. Chondrocytes behaved differently on the two biomaterials. First, in the presence of $\mathrm{PyC}$, the chondrocyte mineralisation ability was greater than in the presence of $\mathrm{CoCr}$. Second, little difference has been detected regarding the matrix biological components of the tissue-like cell membranes. PyC seemed to be more favourable for type II collagen synthesis, characteristic of cartilage extracellular matrix. This observation was further explored with cultures under CLC. Third, the elasticity of the tissue-like cell membrane was higher in contact with PyC than with $\mathrm{CoCr}$, thus, the structures were stiffer. The high variability of the viscosity measurements was probably related to the wide-ranging amounts of medium remaining around the tissue-like cell membranes. It was possible that the higher level of mineralisation contributed to the extracellular matrix stiffening. All the previous results allowed the assertion that under BLC, PyC promoted the creation of a well-organised, wellmineralised and resistant tissue-like cell membrane.

The effect of PyC on chondrocyte behaviour under CLC, as a model for the glenoid cartilage-implant interface, was analysed. In chondrocytes amplified under CLC, TNAP activity and alizarin red staining were maintained at basal levels. At the end of the culture period, chondrocytes produced tissue-like cell membranes with large amounts of extracellular matrix but no mineralisation. The absence of ascorbic acid in the culture medium prevented the formation of a proper collagen fibre organisation, thus blocking a correct analysis of the extracellular matrix. However, immunohistological analysis showed a nett 
increase in type II collagen-positive chondrocytes. As suggested by the results under BLC, PyC seemed to favour type II collagen synthesis. However, more experiments should be performed to further confirm that the chondrocytes grown on PyC under CLC were able to generate a cartilage-like matrix.

The in vivo histologic response of a PyC implant is evaluated in a canine model (Salkeld et al., 2016). A focal PyC hemiarthroplasty is used to replace a full-thickness osteochondral defect in the femoral condyle of the knee and is compared to $\mathrm{CoCr}$ alloy implants. Tibial articular cartilage is assessed after an implantation period of 1 year. The histological scores, which include an evaluation of the extracellular matrix, the presence of cell clusters and the mineralisation grade, are superior for the PyC implants than for the CoCr group. Thus, PyC implants are showed to better retain cartilage properties (Salkeld et al., 2016). A previous study on a similar model shows that PyC implants are better tolerated mechanically as compared to CoCr alloy, particularly because they cause fewer surface cracks (Cook et al., 1999; Cook et al., 1989). Another study shows that the cartilage articulating in the presence of a PyC implant presents lower glycosaminoglycan loss and less abnormal cartilage ossification than with metallic surfaces (Cook et al., 1999). In addition, PyC implants neatly favour fibrocartilage regeneration in comparison to CoCr implants (Kawalec et al., 1998). These in vivo studies corroborate the present study in vitro results on chondrocytes cultured in CLC, suggesting that the use of $\mathrm{PyC}$ might be opportune for cartilage maintenance or regeneration.

The aim of the present study was to investigate the effect of $\mathrm{PyC}$ on chondrocyte behaviour under BLC or CLC in comparison to the more commonly used CoCr. The study demonstrated in vitro that in a cartilage-like environment PyC could promote type II collagen synthesis and that in a bone-like environment, PyC could promote a wellorganised, well-mineralised and stiff tissue-like cell membrane. Thus, the cellular results suggested that PyC could present some benefits for interposition shoulder arthroplasty, which deserve further clinical investigations.

\section{Acknowledgements}

The authors wish to thank the Carnot institute Ingénierie@Lyon (TROPISME) and Wright Medical for their contribution to the funding of this work and for providing the samples. Also, they wish to thank Martine Melin and Aurelie Nallet (Novotec) for their expertise in preparing and analysing the histological sections. Our conflicts of interest are noted as the following: Amira Hannoun, Ghassen Ouenzerfi, Ana-Maria Trunfio-Sfarghiu and Yves Berthier report a grant from Tornier SAS to the LaMCoS during the conduction of the study. Michel Hassler is a Tornier SAS R\&D employee.

\section{References}

Allieu Y (2012) Le concet d'arthroplastie par interposition avec implant libre en pyrocarbone. In: Arthroplasties radiocarpiennes. Fr. Sauramps Médical Montpellier, France: 51-57.

Anselme K (2000) Osteoblast adhesion on biomaterials. Biomaterials 21: 667-681.

Balcerzak M, Hamade E, Zhang L, Pikula S, Azzar G, Radisson J, Bandorowicz-Pikula J, Buchet R (2003) The roles of annexins and alkaline phosphatase in mineralization process. Acta Biochim Pol 50: 10191038.

Behzadi S, Imani M, Yousefi M, Galinetto P, Simchi A, Amiri H, Stroeve P, Mahmoudi M (2012) Pyrolytic carbon coating for cytocompatibility of titanium oxide nanoparticles: a promising candidate for medical applications. Nanotechnology 23: 045102. DOI: 10.1088/0957-4484/23/4/045102.

Boyan BD, Hummert TW, Dean DD, Schwartz Z (1996) Role of material surfaces in regulating bone and cartilage cell response. Biomaterials 17: 137-146.

Chin PYK, Sperling JW, Cofield RH, Schleck C (2006) Complications of total shoulder arthroplasty: Are they fewer or different? J Shoulder Elbow Surg 15: 19-22.

Cook SD, Beckenbaugh RD, Redondo J, Popich LS, Klawitter JJ, Linscheid RL (1999) Long-term follow-up of pyrolytic carbon metacarpophalangeal implants. J Bone Joint Surg Am 81: 635-648.

Cook SD, Thomas KA, Kester MA (1989) Wear characteristics of the canine acetabulum against different femoral prostheses. J Bone Joint Surg Br 71: 189-197.

Cyboron GW, Wuthier RE (1981) Purification and initial characterization of intrinsic membranebound alkaline phosphatase from chicken epiphyseal cartilage. J Biol Chem 256: 7262-7268.

David S J (1999) Dynamic mechanical analysis of polymeric systems of pharmaceutical and biomedical significance. Int J Pharm 179: 167-178.

Edston E, Gröntoft L (1997) Saffron - a connective tissue counterstain in routine pathology. J Histotechnol 20: 123-125.

Fakhry M, Roszkowska M, Briolay A, Bougault C, Guignandon A, Diaz-Hernandez JI, DiazHernandez M, Pikula S, Buchet R, Hamade E, Badran B, Bessueille L, Magne D (2017) TNAP stimulates vascular smooth muscle cell trans-differentiation into chondrocytes through calcium deposition and BMP2 activation: Possible implication in atherosclerotic plaque stability. Biochim Biophys Acta Mol Basis Dis 1863: 643-653.

Garret J, Godeneche A, Boileau P, Molé D, Etzner M, Favard L, Levigne C, Sirveaux F, Gauci M-O, Dezaly C, Walch G (2017) Pyrocarbon interposition shoulder arthroplasty: preliminary results from a prospective multicenter study at 2 years of follow-up. J Shoulder Elbow Surg 26: 1-9.

Gauci MO, Winter M, Dumontier C, Bronsard N, Allieu Y (2016) Clinical and radiologic outcomes of 
pyrocarbon radial head prosthesis: midterm results. J Shoulder Elbow Surg 25: 98-104.

Gittens RA, Olivares-Navarrete R, Schwartz Z, Boyan BD (2014) Implant osseointegration and the role of microroughness and nanostructures: lessons for spine implants. Acta Biomater 10: 3363-3371.

Gonzalez J-F, Alami GB, Baque F, Walch G, Boileau P (2011) Complications of unconstrained shoulder prostheses. J Shoulder Elbow Surg 20: 666682.

Goodman SL, Tweden KS, Albrecht RM (1996) Platelet interaction with pyrolytic carbon heart-valve leaflets. J Biomed Mater Res 32: 249-258.

Gosset M, Berenbaum F, Thirion S, Jacques C (2008) Primary culture and phenotyping of murine chondrocytes. Nat Protoc 3: 1253-1260.

Gouttenoire J, Bougault C, Aubert-Foucher E, Perrier E, Ronzière M-C, Sandell L, LundgrenAkerlund E, Mallein-Gerin F (2010) BMP-2 and TGF- $\beta 1$ differentially control expression of type II procollagen and $\alpha 10$ and $\alpha 11$ integrins in mouse chondrocytes. Eur J Cell Biol 89: 307-314.

Gras M, Wahegaonkar AL, Mathoulin C (2012) Treatment of avascular necrosis of the proximal pole of the scaphoid by arthroscopic resection and prosthetic semireplacement arthroplasty using the pyrocarbon adaptive proximal scaphoid implant (APSI): long-term functional outcomes. J Wrist Surg 1: $159-164$.

Hoemann CD, Lafantaisie-Favreau C-H, LascauComan V, Chen G, Guzmán-Morales J (2012) The cartilage-bone interface. J Knee Surg 25: 85-97.

Hudek R, Werner B, Abdelkawi AF, Gohlke F (2017) Pyrocarbon interposition shoulder arthroplasty in advanced collapse of the humeral head. Orthopade 46: 1034-1044.

Jacobson JA, Duquin TR, Sanchez-Sotelo J, Schleck CD, Sperling JW, Cofield RH (2014) Anatomic shoulder arthroplasty for treatment of proximal humerus malunions. J Shoulder Elbow Surg 23: 1232 1239.

Kawalec JS, Hetherington VJ, Melillo TC, Corbin $N$ (1998) Evaluation of fibrocartilage regeneration and bone response at full-thickness cartilage defects in articulation with pyrolytic carbon or cobaltchromium alloy hemiarthroplasties. J Biomed Mater Res 41: 534-540.

Langenbach F, Handschel J (2013) Effects of dexamethasone, ascorbic acid and $\beta$-glycerophosphate on the osteogenic differentiation of stem cells in vitro. Stem Cell Res Ther 4: 117.

Leboy PS, Sullivan TA, Menko AS, Enomoto M (1992) Ascorbic acid induction of chondrocyte maturation. Bone Miner 17: 242-246.

Lévigne C, Lacroix P, Garret J (2010) Shoulder arthroplasty in 2010 anatomical or reversed prosthesis? Indications and contra-indications Rev du Rhum Monogr 77: 195-200

Levy O, Copeland S a (2001) Cementless surface replacement arthroplasty of the shoulder. 5- to 10- year results with the Copeland mark-2 prosthesis. J Bone Joint Surg. Br 83: 213-221.

Lewallen EA, Riester SM, Bonin CA, Kremers HM, Dudakovic A, Kakar S, Cohen RC, Westendorf JJ, Lewallen DG, van Wijnen AJ (2014) Biological strategies for improved osseointegration and osteoinduction of porous metal orthopedic implants. Tissue Eng Part B Rev 21: 218-230.

Moorehead WR, Biggs HG (1974) 2-amino2-methyl-1-propanol as the alkalizing agent in an improved continuous-flow cresolphthalein complexone procedure for calcium in serum. Clin Chem 20: 1458-1460.

Mosmann T (1983) Rapid colorimetric assay for cellular growth and survival: application to proliferation and cytotoxicity assays. J Immunol Methods 65: 55-63.

Ozturk Tc, Guneysel O, Akoglu H (2014) Anterior shoulder dislocation reduction managed either with midazolam or propofol in combination with fentanyl. Hong Kong J Emerg Med 21: 346.

Salkeld SL, Patron LP, Lien JC, Cook SD, Jones DG (2016) Biological and functional evaluation of a novel pyrolytic carbon implant for the treatment of focal osteochondral defects in the medial femoral condyle: assessment in a canine model. J Orthop Surg Res 11: 155.

Stanford CM, Jacobson PA, Eanes ED, Lembke LA, Midura RJ (1995) Rapidly forming apatitic mineral in an osteoblastic cell line (UMR 106-01 BSP). J Biol Chem 270: 9420-9428.

Wiater BP, Moravek JE, Wiater JM (2014) The evaluation of the failed shoulder arthroplasty. J Shoulder Elbow Surg 23: 745-758.

Wiater MJ, Fabing MH (2009) Shoulder arthroplasty: prosthetic options and indications. J Am Acad Orthop Surg 17: 415-425.

\section{Discussion with Reviewer}

Tony Chen: A very interesting finding of the study is that the addition of ascorbic acid in mouse chondrocytes leads to an increase in alkaline phosphatase, while providing rationale for not using it. Xu et al. (1994, additional reference) find that alkaline phosphatase expression decreases with time in culture. Could the response you observed also be similar (e.g. longer culture, less alkaline phosphatase)?

Authors: In the presented cell model of primary mouse chondrocytes, addition of ascorbic acid progressively increased alkaline phosphatase activity over a 17-d long period and the culture duration was not further extended. However, in the near model of primary mouse osteoblasts (Bougault et al., 2015, additional reference), alkaline phosphatase activity was augmented during the first $17 \mathrm{~d}$ of the culture but was maintained at a constant level when the culture was extended for another $4 \mathrm{~d}$. 
Tony Chen: Is there any dynamic motion added to the ex vivo PyC culturing system to simulate the movement of the joint? Or was the culture performed in static conditions? What do you think the effects of motion would be if you are not already including this?

Authors: There was no dynamic motion added to the ex vivo PyC culturing system: the cell culture was only performed in static conditions. However, it is true that mechanical stress is one of the environmental factors that strongly impacts cell behaviour at the site of the implant. In the present study, cell culture in presence of PyC combined with dynamic mechanical stimulation (like compression and shear stress) obtained in a 'tribo-bioreactor' stimulated cartilagelike tissue production.

\section{Additional reference}

Bougault C, Briolay A, Boutet M-A, Pilet P, Delplace S, Le Goff B, Guicheux J, Blanchard F, Magne $\mathrm{D}$ (2015) Wnt5a is expressed in spondyloarthritis and exerts opposite effects on enthesis and bone in murine organ and cell cultures. Transl Res 166: 627-638.

Xu Y, Pritzker KP, Cruz TF (1994) Characterization of chondrocyte alkaline phosphatase as a potential mediator in the dissolution of calcium pyrophosphate dihydrate crystals J Rheumatol 21: 912-919.

Editor's note: The Scientific Editor responsible for this paper was Stephen Ferguson. 